\title{
Role of angiopoietin-2 in the cardioprotective effect of fibroblast growth factor 21 on ischemia/reperfusion-induced injury in $\mathrm{H9c2}$ cardiomyocytes
}

\author{
SHUOQIANG HU ${ }^{1}$, SHUJUN CAO ${ }^{2}$ and JINGHUA LIU ${ }^{1}$ \\ ${ }^{1}$ Department of Cardiology, Beijing Anzhen Hospital, Capital Medical University, \\ Beijing Institute of Heart, Lung and Blood Vessel Diseases, Beijing 100029; ${ }^{2}$ Department of Cardiology, \\ Beijing Daxing Hospital, Capital Medical University, Beijing 102600, P.R. China \\ Received February 18, 2016; Accepted February 10, 2017
}

DOI: $10.3892 /$ etm.2017.4564

\begin{abstract}
Fibroblast growth factor 21 (FGF21) exerts a protective effect in ischemia/reperfusion (I/R)-induced cardiac injury. However, the exact molecular mechanism underlying the FGF21 action remains unclear. The present study aimed to evaluate the role of angiopoietin-2 (Angpt2) in the cardioprotective effect of FGF21. For this purpose, the H9C2 cell line was subjected to simulated I/R or aerobic conditions with or without FGF21 administration. Certain groups were also transfected with Angpt 2 small interfering RNA (siRNA). Cell viability, apoptosis rate and cell migration were examined, and the expression levels of Angpt2, glucose transporter 1 (GLUT1) and caspase-3 were measured by quantitative polymerase chain reaction (qPCR) and western blot analyses. The results demonstrated that FGF21 administration suppressed apoptosis and increased the cell migration ability following I/R-induced injury. qPCR and western blot data showed a decreased level of GLUT1 after I/R-induced injury, which was reversed by FGF21 administration. Furthermore, inhibition of Angpt 2 expression using siRNA enhanced the cardioprotective effect of FGF21 by upregulation of GLUT1. In conclusion, FGF21 administration protected against I/R-induced injury in cardiomyocytes, and further inhibition of Angpt2 with FGF21 administration induced the expression of GLUT1, which may promote the energy metabolism in cardiomyocytes, consequently resulting in a more efficient cardioprotective effect. These results suggested that FGF21 administration and inhibition of Angpt 2 could be a novel therapeutic approach for I/R-induced cardiac injury.
\end{abstract}

Correspondence to: Dr Jinghua Liu, Department of Cardiology, Beijing Anzhen Hospital, Capital Medical University, Beijing Institute of Heart, Lung and Blood Vessel Diseases, 2 Anzhen Road, Chaoyang, Beijing 100029, P.R. China

E-mail: liujinghua@vip.sina.com

Key words: fibroblast growth factor 21, H9c2, angiopoietin-2, myocardial ischemia/reperfusion injury, apoptosis

\section{Introduction}

Among all types of heart disease, ischemic heart disease, also known as coronary heart disease, is the main cause of morbidity and mortality (1). Shortage of blood supply to the heart resulting in irreversible cardiomyocyte death and eventually leading to myocardial infarction is the common pathway of ischemic heart disease. Different forms of reperfusion therapy, including coronary angioplasty, coronary stenting and coronary revascularization, as well as pharmacological adjuvants are widely used in clinical practice for the treatment of this disease (2). However, ischemia/reperfusion (I/R)-induced injury due to the restoration of blood supply to the ischemic area occurs subsequent to reperfusion therapy, leading to acute tissue damage (3). Present therapeutic strategies are not efficient in preventing I/R-induced injury. Therefore, the development of novel strategies focusing on the prevention of $\mathrm{I} / \mathrm{R}$-induced injury is crucial for the treatment of ischemic heart disease.

Several mediators of I/R-induced injury have been established, including inflammatory cells (such as T-cells) (4), proteolytic enzymes (such as MMP2 and MMP-9) (5) and kinases (such as Rho kinase) (6). In addition, a number of pharmacological compounds targeting these mediators have been reported to improve cardiac function and attenuate I/R-induced injury (7).

Recently, an endocrine factor, fibroblast growth factor 21 (FGF21), has received increasing attention. FGF21 belongs to the family of 22 fibroblast growth factors, and is mainly expressed in the liver and adipose tissue (8). FGF21, as a key metabolic regulator, stimulates cell glucose uptake by inducing the expression of glucose transporter-1 (GLUT1) and insulin. In addition, it has been demonstrated that FGF21 is involved in the suppression of the downstream signaling of apoptosis (9). Recent studies have provided evidence supporting that endocrine FGF21 protects against myocardial apoptosis caused by I/R-induced injury, possibly through the fibroblast growth factor receptor (FGFR)-PIK3-AKT-caspase-3 signaling pathway (10). FGFRs are well-known FGF-specific receptor tyrosine kinases, which serve a fundamental role in the onset of this signaling pathway triggered by FGF21 (11). By contrast, 
antagonists of tyrosine kinases may inhibit or at least attenuate the protective effect of FGF21. Further investigations are required to determine the mechanism underlying the protective effect of FGF21.

Angiopoietin-2 (Angpt2) has been examined in different heart disease models, suggesting that Angpt 2 is an important regulator in the injury heart $(12,13)$, which may be a promising predictor of heart disease (14). Angpt2 is generally considered as a natural antagonist of angiopoietin-1 (Angpt1) and TEK tyrosine kinase, and it competitively inhibits the binding of Angpt1 and TEK tyrosine kinase, thus disrupting the downstream signaling and leading to endothelial damage and vessel leakage (15). Angpt2 has proinflammatory and apoptosis-promoting abilities, further impairing the vascular tissue (15). Furthermore, it has been reported that Angpt2 interacts with other classes of tyrosine kinases, such as FGFRs (16). However, no previous studies have investigated whether Angpt 2 affects the protective effect of FGF21 via inhibiting FGFR signaling-induced GLUT1 overexpression.

Therefore, the present study sought to elucidate the role of Angpt2 in the protective effect of FGF21 administration on I/R-induced injury in cardiomyocytes. It was hypothesized that upregulation of Angpt 2 during I/R-induced injury may attenuate the cardioprotective effect of FGF21 via the suppression of GLUT1 expression, and that application of Angpt 2 small interfering RNA (siRNA) along with FGF21 administration may result in more efficient protection against I/R-induced injury.

\section{Materials and methods}

Chemicals and cell culture. Antibodies against Angpt2 (ab8452), GLUT1 (ab652) and caspase-3 (ab13847) were purchased from Abcam (Cambridge, MA, USA). Human recombinant protein FGF21 was purchased from Abnova (Walnut, CA, USA; purity $>95 \%$ ). The H9c2 cardiomyocyte line (obtained from American Type Culture Collection, Manassas, VA, USA) was cultured in Dulbecco's modified Eagle's medium (DMEM) with $10 \%$ (v/v) fetal bovine serum (FBS), $100 \mathrm{U} / \mathrm{ml}$ penicillin and $100 \mathrm{mg} / \mathrm{ml}$ streptomycin. $\mathrm{H} 9 \mathrm{c} 2$ cells were incubated in a $5 \% \mathrm{CO}_{2}$ incubator at $37^{\circ} \mathrm{C}$. After $70-80 \%$ confluence was reached, cells were subjected to trypsinization, according to standard procedures. Cells were then harvested in DMEM with $1 \% \mathrm{FBS}$ and stored at $-80^{\circ} \mathrm{C}$ for subsequent biochemistry analysis.

Establishment of a stimulated I/R model in H9c2 cardiomyocytes. In order to mimic I/R-induced injury in vitro, simulated ischemia followed by reperfusion were performed in $\mathrm{H} 9 \mathrm{c} 2$ cells (17). Cells were transferred to an ischemia-simulating buffer solution (137 mM NaCl, $12 \mathrm{mM} \mathrm{KCl,} 0.49 \mathrm{mM} \mathrm{MgCl}_{2}$, $0.9 \mathrm{mMCaCl}_{2} \cdot 2 \mathrm{H}_{2} \mathrm{O}, 4 \mathrm{mMHEPES}$ and $20 \mathrm{mM}$ sodium lactate), and then placed in a sealed hypoxia chamber (containing $95 \% \mathrm{~N}_{2}$ and $5 \% \mathrm{CO}_{2}$ ) for $4 \mathrm{~h}$ at $37^{\circ} \mathrm{C}$ to induce anoxia. Cells were treated for 4,6 and $8 \mathrm{~h}$ of simulated ischemia. Subsequent to simulated ischemia, the medium was replaced by normal medium, and cells were incubated in a $5 \% \mathrm{CO}_{2}$ incubator at $37^{\circ} \mathrm{C}$ for $24 \mathrm{~h}$ to simulate reperfusion.

siRNA transfection assay. The specific Angpt2 siRNA was synthesized chemically, and the sequences targeting Angpt2 were 5'-GAUCGAGAUUGGAACCAGUTT-3' (sense) and 5'-ACUGGUUCCAAUCUCGAUCTT-3' (antisense). In addition, nonsilencing siRNA was used as a negative control (NC), in order to determine whether there were any other effects induced by the siRNA and transfection reagents. The sequences of the control siRNA were 5'-UUCUCCGAACGUGUCACG UTT-3' (sense) and 5'-ACGUGACACGUUCGGAGAATT-3' (antisense). Angpt2 siRNA group was transfected with Angpt2 siRNA and control group was transfected with non-silencing siRNA using Lipofectamine ${ }^{\circledR} 2000$ reagent (Invitrogen; Thermo Fisher Scientific, Inc., Waltham, MA, USA) according to the manufacturer's protocols. The non-siRNA control group had similar results to the non-silencing siRNA control group (data not shown), therefore only the results of the non-silencing siRNA control group are presented.

Cell counting kit 8 (CCK-8) assay. CCK-8 assay (ab65314; Abcam) was used to evaluate cell proliferation according to the manufacturer's protocol. Briefly, H9c2 cells were cultured at a density of of $5 \times 10^{4}$ cells/well in 96-well culture dish. After 24 h, adherence was observed, and cells were subjected to the simulated I/R model as indicated earlier, and treated with FGF21 and Angpt2 siRNA as appropriate. Experimental groups include: i) At normal aerobic conditions, different incubation durations $(24,48$ and $72 \mathrm{~h})$ and concentrations $(0$, $0.25,0.5,1$ and $2 \mu \mathrm{g} / \mathrm{ml}$ ) of FGF21 were tested to determine for the treatment model; ii) normal conditions were used for the control group, and I/R group was compared with I/R + FGF21 group; iii) I/R-treated cells with non-silencing siRNA transfection were used as a negative control, I/R + Angpt 2 siRNA group was compared with I/R + Angpt2 siRNA + FGF21 group. At the end of each experiment, $10 \mu \mathrm{l}$ CCK- 8 solution was added to each well, and then the cells were further incubated for $1 \mathrm{~h}$ at $37^{\circ} \mathrm{C}$. The absorbance of samples at $450 \mathrm{~nm}$ was determined by a multi-well plate reader.

Apoptosis assay by flow cytometry. Apoptosis was determined by Annexin V and propidium iodide (PI) double staining (v13242; Invitrogen, Thermo Fisher Scientific, Inc.). Briefly, following the various experimental treatments, cells were detached with trypsin-EDTA, washed twice with phosphate-buffered saline (PBS), resuspended in binding buffer (10 mM HEPES pH 7.4, $150 \mathrm{mM} \mathrm{NaCl}, 5 \mathrm{mM} \mathrm{KCl}, 1 \mathrm{mM} \mathrm{MgCl}{ }_{2}$ and $1.8 \mathrm{mM} \mathrm{CaCl}_{2}$ ) containing FITC-Annexin $\mathrm{V}(1 \mathrm{~g} / \mathrm{ml})$ and then further incubated for $20 \mathrm{~min}$. At $10 \mathrm{~min}$ before the end of incubation, PI $(10 \mathrm{~g} / \mathrm{ml})$ was added to this cell suspension in order to stain necrotic cells. Cells were analyzed with a FACScan flow cytometer equipped with an excitation laser line at $488 \mathrm{~nm}$. The PI was analyzed using a $575 \mathrm{~nm}$ band pass filter.

Cell cycle analysis using flow cytometry. After I/R treatment, cells were harvested, washed with cold PBS, and fixed with $70 \%$ ethanol overnight at $-20^{\circ} \mathrm{C}$. The fixed cells were then washed twice with cold PBS, then subjected to centrifugation for $20 \mathrm{~min}$ at $15,000 \times \mathrm{g}$ at $4^{\circ} \mathrm{C}$, and the supernatant was discarded. Next, the cells were stained with PI staining solution $(10 \mu \mathrm{g} / \mathrm{ml} \mathrm{RNase} \mathrm{A}$ and $50 \mu \mathrm{g} / \mathrm{ml} \mathrm{PI})$ at $37^{\circ} \mathrm{C}$ for $30 \mathrm{~min}$ in the dark. The cell cycle distribution was analyzed by flow cytometry using CellQuest software 5.1 (BD Biosciences, San Jose, CA, USA). 
Cell migration investigation by Transwell assay. To examine cell migration, cells were transferred to the Transwell ${ }^{\circledR}$ inserts of a 24-well plate, and subjected to $6 \mathrm{~h}$ simulated ischemia followed by $24 \mathrm{~h}$ reperfusion. The Transwell insert was then washed three times with PBS, and the cells on the top surface of the insert were removed with a cotton swab. Cells adhering to the lower surface were fixed with methanol for $10 \mathrm{~min}$, stained with $0.1 \%$ Giemsa solution for $10 \mathrm{~min}$, washed three times with PBS and air-dried. The migrating cells were counted and images were captured using a microscope (Nikon Corp., Tokyo, Japan). All experiments were performed in triplicate and ten fields of vision were counted per filter in each group.

Gene expression analysis using reverse transcriptionquantitative polymerase chain reaction (RT-qPCR). The total RNA from H9c2 cells in the various treatment groups was extracted using TRIzol kit (Invitrogen, Thermo Fisher Scientific, Inc.) according to the manufacturer's instructions. The extracted RNA was measured using UVS-99 Micro-volume UV/Vis Spectrophotometer (ACTGene, Piscataway, NJ, USA). A total of $1 \mu \mathrm{g}$ RNA was reverse transcribed into cDNA using oligo (dT) primer and SuperScript III reverse transcriptase (Invitrogen, Thermo Fisher Scientific, Inc.). qPCR was performed with an ABI 7500 Real-Time PCR System (Applied Biosystems; Thermo Fisher Scientific, Inc.). Target cDNA levels were determined by SYBR-Green-based qPCR in 20- $\mu$ l reactions, containing $10 \mu \mathrm{l}$ Power SYBR-Green Master Mix (Applied Biosystems; Thermo Fisher Scientific, Inc.). The following primers were used: Caspase-3 forward, 5'-ATGTCGATGCAGCTAACCTC-3', and reverse, 5'-TCCTTTTGC TGTGATCTTCC-3'; Angpt2 forward, 5'-GGCAGCGTTGAT TTTCAGAGGACT-3', and reverse, 5'-TTTAATGCCGTT GAACTTATTTGT-3'; GLUT1 forward, 5'-CTTCATCCC AGCCCTGTT-3', and reverse, 5'-GACCTTCTTCTCCCG CATC-3'; $\beta$-actin forward, 5'-GCACCACACCTTCTACAA TG-3', and reverse, 5'-TGCTTGCTGATCCACATCTG-3'. PCR cycling was performed as follows: 1 cycle for $2 \mathrm{~min}$ at $94^{\circ} \mathrm{C}$, followed by $29-32$ cycles of $95^{\circ} \mathrm{C}$ for $30 \mathrm{sec}, 57-60^{\circ} \mathrm{C}$ for $45 \mathrm{sec}, 72^{\circ} \mathrm{C}$ for $1 \mathrm{~min}$, followed by 1 cycle of $72^{\circ} \mathrm{C}$ for $5 \mathrm{~min}$, held at $4^{\circ} \mathrm{C}$. The qPCR data were analyzed with the $2^{-\Delta \Delta \mathrm{Cq}}$ method (18) and normalized against $\beta$-actin cDNA, used as an internal control.

Western blot analysis. Cells were harvested and stored at $-80^{\circ} \mathrm{C}$ until further use. For western blot analysis, frozen cells were sonicated on ice twice for $5 \mathrm{sec}$ in $50 \mathrm{mM}$ lysis buffer (Invitrogen; Thermo Fisher Scientific, Inc.), containing $3.1 \mathrm{mM}$ sucrose, $1 \mathrm{mM}$ DTT, $10 \mu \mathrm{g} / \mathrm{ml}$ leupeptin, $10 \mu \mathrm{g} / \mathrm{ml}$ soybean trypsin inhibitor, $2 \mu \mathrm{g} / \mathrm{ml}$ aprotinin and $0.1 \%$ Triton $\mathrm{X}-100$. Homogenates were centrifuged at $10,000 \times \mathrm{g}$ at $4^{\circ} \mathrm{C}$ for $20 \mathrm{~min}$, and the supernatant was collected. The total protein concentration was measured using the Bradford protein assay (Bio-Rad Laboratories, Inc., Hercules, CA, USA). Protein lysates (30 $\mu \mathrm{g})$ were separated using $12 \%$ SDS-PAGE and transferred to a polyvinylidene fluoride (PVDF) membrane. After blocking with 5\% nonfat milk, the PVDF membrane was incubated overnight at $4^{\circ} \mathrm{C}$ with the monoclonal primary antibodies against caspase-3, Angpt2, GLUT1 and GAPDH (all 1:1,000) diluted in Tris-buffered saline with Tween-20 (TBS-T). Membranes were washed in TBS-T (10 min, three times) and then probed with the appropriate secondary antibody (1:10,000; Abcam). Subsequently, membranes were developed using Versa Doc 5000 (Bio-Rad Laboratories, Inc.), and the band densities were measured with Quantity One 4.6 software (Bio-Rad Laboratories, Inc.). Equal protein loading was additionally verified by measurement of GAPDH level with a corresponding mouse monoclonal antibody (1:10,000; ab6708; Abcam).

Statistical analysis. Statistical calculations were performed using Prism 6 (GraphPad Software, Inc., San Diego, CA, USA). Data are presented as the mean \pm standard error of the mean. Student's t-test was used for comparisons between two groups, and one-way or two-way analysis of variance was used for comparisons among multiple groups. Differences with $\mathrm{P}<0.05$ were considered as statistically significant.

\section{Results}

Effect of various FGF21 concentrations and incubation durations on cell viability. The effect of incubation duration and concentration of FGF21 on H9c2 cell viability was determined by CCK- 8 assay. The results indicated that cells treated with $1 \mu \mathrm{g} / \mathrm{ml} \mathrm{FGF} 21$ for $48 \mathrm{~h}$ exhibited the highest cell viability and proliferation (Fig. 1; $\mathrm{P}<0.01$ ). Therefore, cells were treated with the optimized FGF21 concentration of $1 \mu \mathrm{g} / \mathrm{ml}$ for $48 \mathrm{~h}$ in subsequent experiments, as the FGF21-treatment group.

Determination of simulate I/R model setup. The effect of the ischemia duration on the apoptosis rate was also measured. The results indicated that $4 \mathrm{~h}$ of ischemia resulted in $20 \%$ of apoptosis (Fig. 2). With longer duration of ischemia, the cells were significantly further damaged $(\mathrm{P}<0.01)$, and demonstrated apoptosis rate of 40 and $60 \%$ for 6 and $8 \mathrm{~h}$ of ischemia, respectively (Fig. 2). Based on the apoptosis rate ( $\sim 50 \%$ is appropriate for an I/R-induced injury model), $6 \mathrm{~h}$ ischemia followed by $24 \mathrm{~h}$ reperfusion was selected for further experiments.

Effect of FGF21 on cell survival. The effect of simulated I/R on cell viability was determined by CCK-8 assay. As shown in Fig. 3A, simulated I/R significantly decreased the cell viability by $\sim 50 \%$ in comparison with the control group that was treated under aerobic conditions $(\mathrm{P}<0.01)$. By contrast, exposure to $1 \mu \mathrm{g} / \mathrm{ml}$ FGF21 after simulated I/R had a protective effect against injury, since it significantly increased the cell viability in comparison with the I/R model group $(\mathrm{P}<0.01)$.

The cell cycle and apoptosis rate were subsequently determined by flow cytometry. Cell cycle distribution was not significantly affected by I/R and FGF21 administration (Fig. 3B). The cell apoptosis rate was significantly increased in the simulated $\mathrm{I} / \mathrm{R}$ group when compared with that of the aerobic control group, with $\sim 40 \%$ apoptotic cells detected $(\mathrm{P}<0.01)$. However, FGF21 demonstrated an evident apoptosis-inhibiting effect after simulated I/R, with a significant reduction of the apoptosis rate observed in the FGF21-treated group when compared with the I/R model group $(\mathrm{P}<0.01$; Fig. 3C).

Effect of FGF21 on cell migration. Data from the Transwell migration assay demonstrated that the cell migration ability 


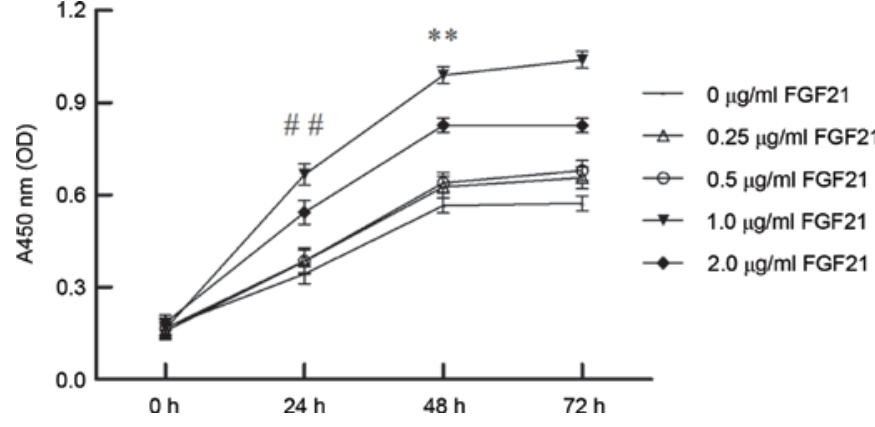

Figure 1. Determination of the most effective incubation duration and FGF21 concentration. Cell counting kit-8 assay was performed for $0,24,48$ and $72 \mathrm{~h}$ with different concentration of FGF21 $(0,0.25,0.5,1.0$ and $2.0 \mu \mathrm{g} / \mathrm{ml})$. The results are the mean of three independent experiments. ${ }^{* *} \mathrm{P}<0.01 \mathrm{vs}$. all other FGF21 concentrations at $48 \mathrm{~h} ;{ }^{\#} \mathrm{P}<0.01$ vs. all other FGF21 concentrations at 24 h. FGF21, fibroblast growth factor 21.
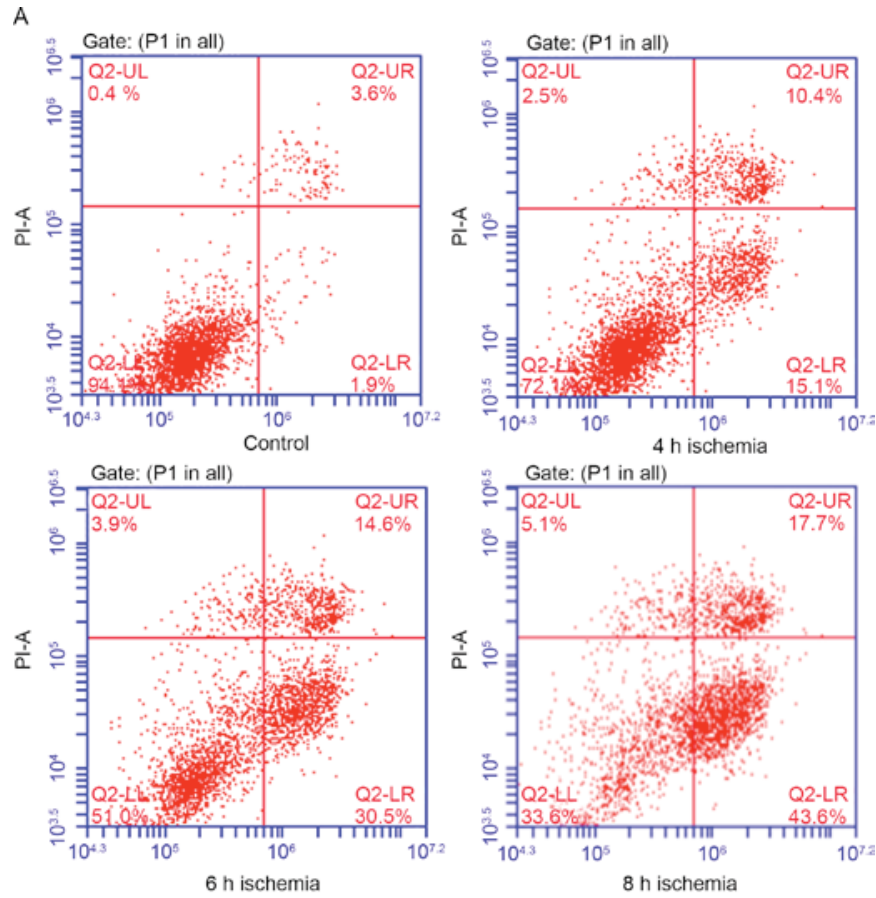

B

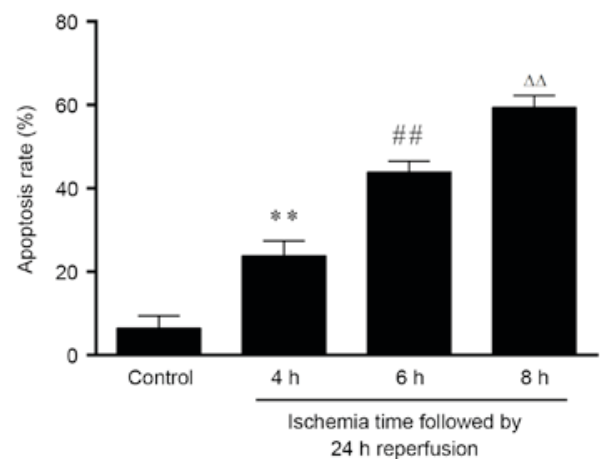

Figure 2. Determination of the most appropriate ischemia duration, according to the apoptosis rate detected by flow cytometry. (A) Flow cytometry graphs and (B) quantified apoptosis rates are shown. Cells were treated with simulated ischemia $(4,6$ and 8 h) followed by $24-h$ reperfusion $(n=3)$. In flow cytometry graphs, the lower right quadrant indicated early apoptotic cells, while the upper right quadrant indicated necrotic and late apoptotic cells. Early and late apoptotic cells were considered as the incidence of apoptotic cell death. ${ }^{* *} \mathrm{P}<0.01$ vs. control, ${ }^{\# \#} \mathrm{P}<0.01$ vs. $4 \mathrm{~h}$ ischemia and ${ }^{\Delta \Delta} \mathrm{P}<0.01$ vs. $6 \mathrm{~h}$ ischemia. FGF21, fibroblast growth factor 21.
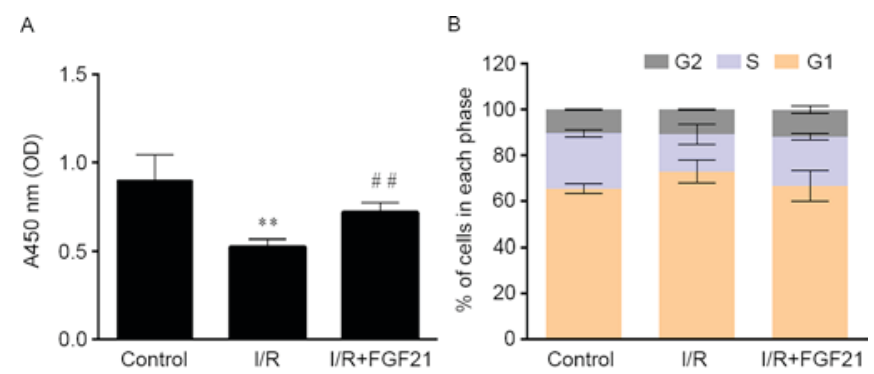

C
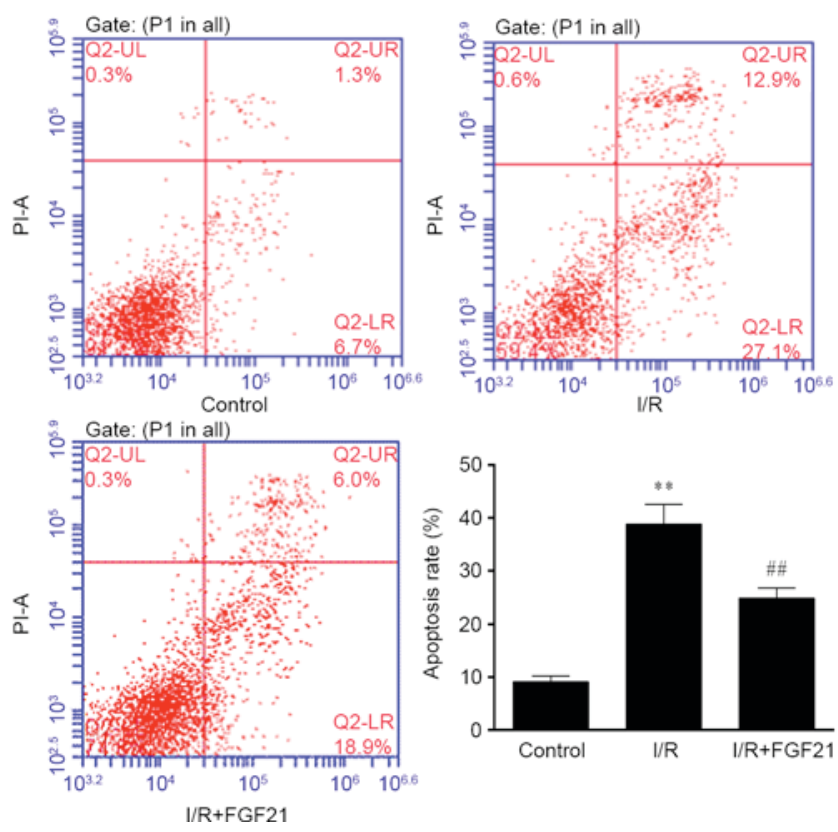

Figure 3. Effect of FGF21 on cell survival. (A) Cell viability in each group was measured by the cell counting kit- 8 assay. (B) Cell cycle distribution and (C) apoptosis rate of each group were detected by flow cytometry. The results are representative of the mean of three independent experiments. ${ }^{* *} \mathrm{P}<0.01$ vs. the control group; ${ }^{\#} \mathrm{P}<0.01$ vs. the I/R group. FGF21, fibroblast growth factor $21 ; \mathrm{I} / \mathrm{R}$, ischemia/reperfusion.

was significantly decreased by $>50 \%$ following simulated I/R, when compared with that of the aerobic control group $(\mathrm{P}<0.01$; Fig. 4). However, FGF21 treatment enhanced the cell migration ability during I/R-induced injury, with a significantly higher number of migrated cells detected as compared with the $\mathrm{I} / \mathrm{R}$ model group $(\mathrm{P}<0.01)$.

Effect of FGF21 on the protein and mRNA levels of caspase-3, Angpt 2 and GLUT1. The protein expression levels of caspase-3, Angpt 2 and GLUT1 were evaluated by western blot analysis. Measurement of the GAPDH level was used as a control for equal protein loading. In comparison with the aerobic control group, the protein levels of caspase- 3 and Angpt 2 were markedly increased following simulated $\mathrm{I} / \mathrm{R}$, whereas the level of GLUT1 was decreased (Fig. 5A). In the FGF21-treated group, the expression levels of caspase-3 and Angpt 2 were downregulated following simulated I/R, while the expression of GLUT1 was upregulated.

RT-qPCR was further performed to determine the gene expression levels of caspase-3, Angpt 2 and GLUT1, and the results were similar to those obtained from western blot analysis 


\section{A}

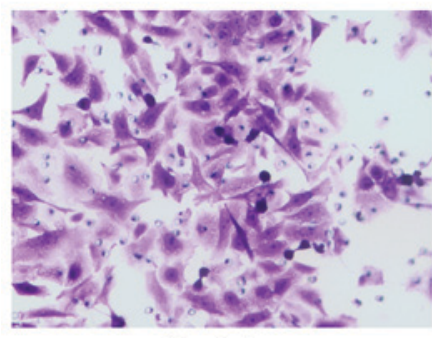

Control

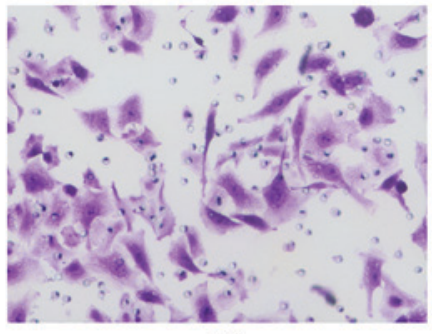

I/R

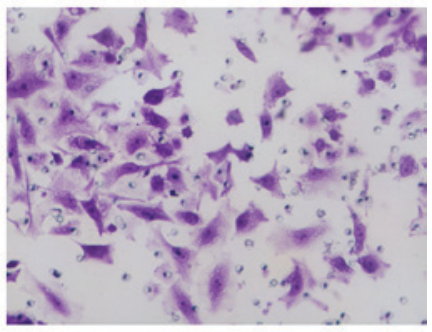

l/R+FGF21

B

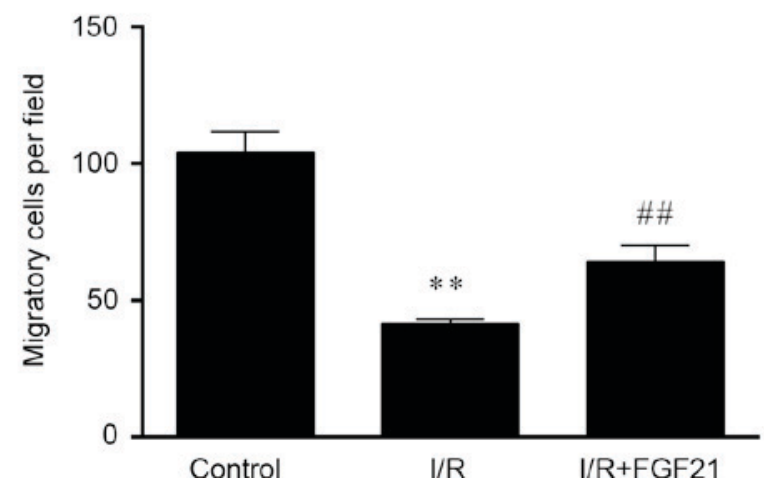

Figure 4. Effect of FGF21 on cell migration. (A) Representative images of five independent experiments of Transwell cell migration assay are shown for the control, I/R and I/R+FGF21 groups. (B) Mean cell migration per field ( $\mathrm{n}=5$ ) is illustrated. ${ }^{* *} \mathrm{P}<0.01$ vs. the control group; ${ }^{\# / t} \mathrm{P}<0.01$ vs. the $\mathrm{I} / \mathrm{R}$ group. FGF21, fibroblast growth factor $21 ; \mathrm{I} / \mathrm{R}$, ischemia/reperfusion.

A
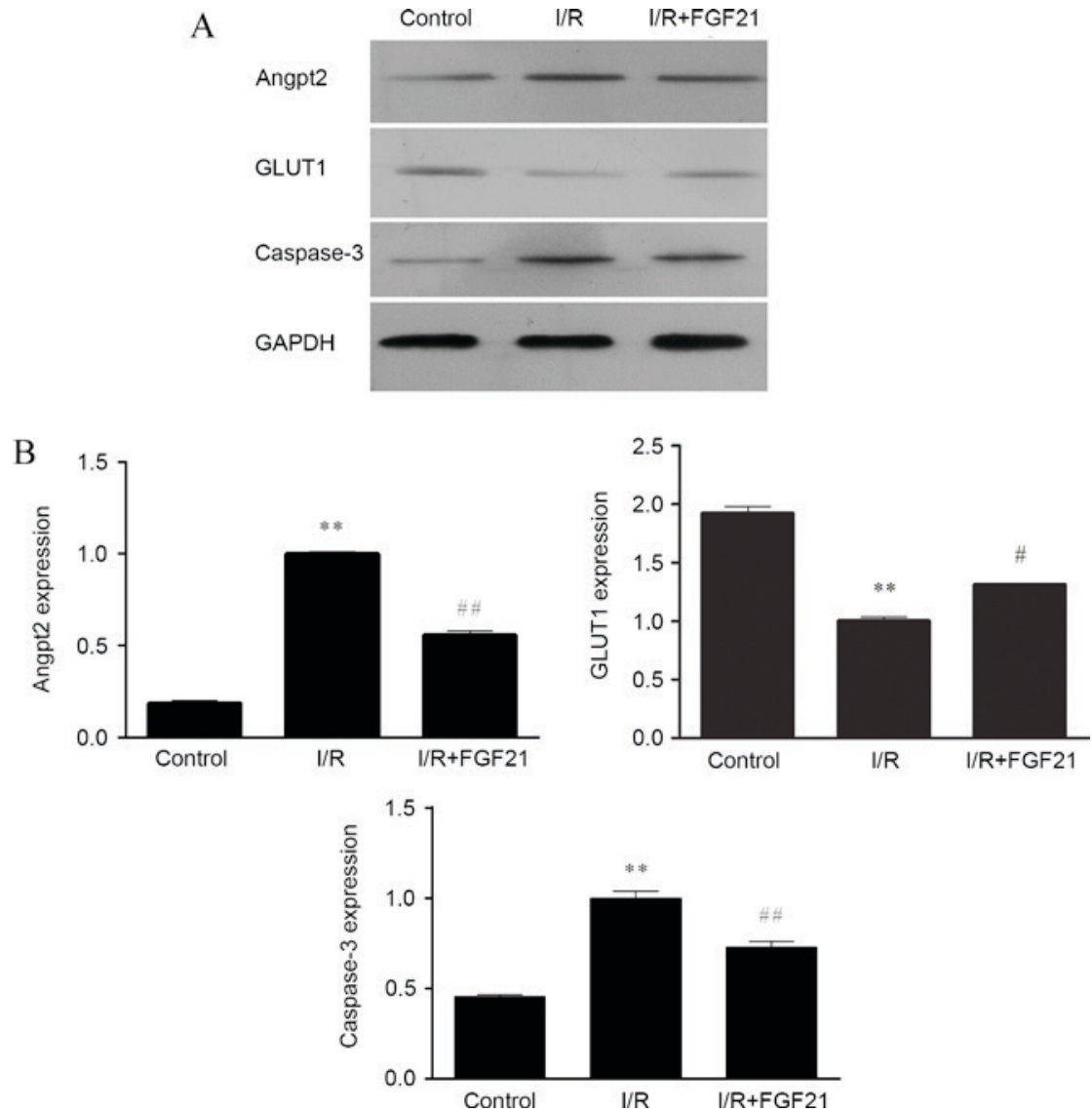

Figure 5. Effect of FGF21 on the (A) protein and (B) gene expression levels of Angpt2, GLUT1 and caspase-3, determined by western blot analysis and qPCR, respectively. In western blot analysis, equal protein loading was verified by measurement of the GAPDH level. In qPCR, relative expression is given as the mean of four independent experiments. ${ }^{* *} \mathrm{P}<0.01$ vs. the control group; ${ }^{*} \mathrm{P}<0.05$ and ${ }^{\# \# /} \mathrm{P}<0.01$ vs. the I/R group. FGF21, fibroblast growth factor $21 ; \mathrm{I} / \mathrm{R}$, ischemia/reperfusion; qPCR, quantitative polymerase chain reaction; Angpt2, angiopoietin-2; GLUT1, glucose transporter 1. 
A
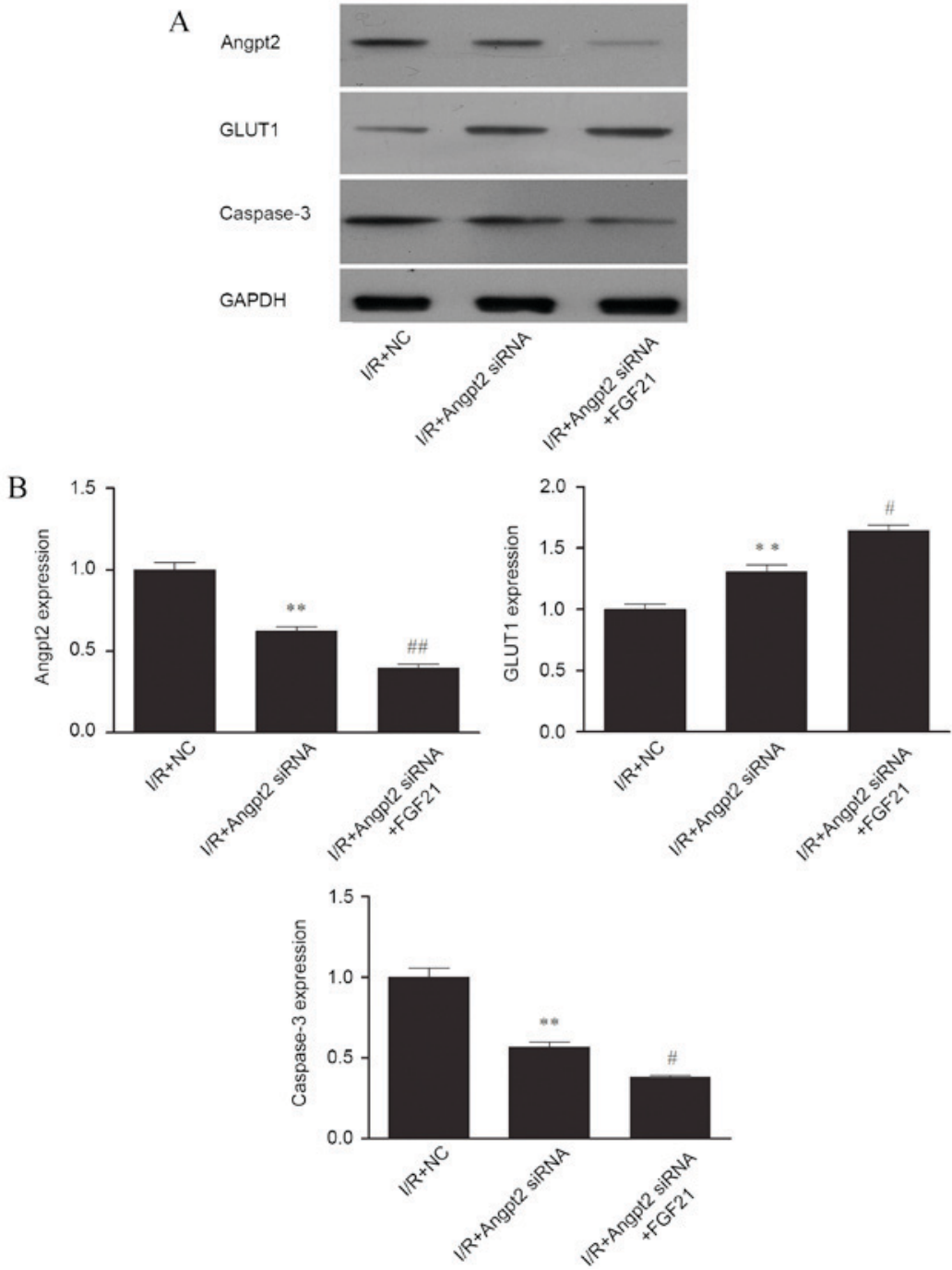

Figure 6. Effect of Angpt2 siRNA transfection and FGF21 treatment on the (A) protein and (B) gene expression levels of Angpt2, GLUT1 and caspase-3, determined by western blot analysis and qPCR, respectively. In western blot analysis, equal protein loading was verified by measurement of the GAPDH level. In qPCR, relative expression is given as the mean of four independent experiments. ${ }^{* *} \mathrm{P}<0.01$ vs. the $\mathrm{I} / \mathrm{R}+\mathrm{NC}$ group; ${ }^{\#} \mathrm{P}<0.05$ and ${ }^{\# \#} \mathrm{P}<0.01 \mathrm{vs}$. the I/R + Angpt 2 siRNA group. FGF21, fibroblast growth factor 21; I/R, ischemia/reperfusion; qPCR, quantitative polymerase chain reaction; Angpt2, angiopoietin-2; GLUT1, glucose transporter 1; siRNA, small interfering RNA; NC, negative control.

(Fig. 5B). Significantly increased gene expression of caspase-3 and Angpt2, and significantly decreased gene expression of GLUT1 were observed in the simulated I/R group compared with the control (all $\mathrm{P}<0.01$ ). By contrast, in the FGF21 treated group, the gene expression levels of caspase-3 and Angpt2 were significantly downregulated in comparison with those in the I/R model group $(\mathrm{P}<0.01)$ and GLUT1 was significantly upregulated $(\mathrm{P}<0.05)$.

Influence of Angpt 2 inhibition on the protective effect of $F G F 21$ against I/R injury. The results of the negative control siRNA transfected cells and normal control cells did not differ in all experimental groups (data not shown). Therefore, the negative control siRNA transfected cells treated by simulated I/R were used as a control in all siRNA transfection experiments.

Knockdown of Angpt2 expression by the Angpt2 siRNA was evaluated by western blot analysis. Following simulated $\mathrm{I} / \mathrm{R}$, the Angpt2 protein expression in the Angpt2 siRNA transfected group was reduced by $\sim 50 \%$ in comparison to control cells (Fig. 6A). A lower level of caspase-3 was also observed in the Angpt2 siRNA transfected group, while the level of GLUT1 was increased compared with the I/R model group (Fig. 6A). Similar observations were obtained for the mRNA expression levels of Angpt2, caspase-3 and GLUT1 by RT-qPCR analysis, with significant differences observed in the Angpt2 siRNA group compared with the control (all $\mathrm{P}<0.01$; Fig. 6B).

Western blot analysis also indicated that FGF21 administration with Angpt2 knockdown further inhibited the protein expression levels of Angpt 2 and caspase-3 in comparison with the control after simulated I/R. A much larger increase of GLUT1 expression was also observed in the FGF21 + Angpt2 siRNA treated group (Fig. 6A). Similar observations were obtained for the mRNA expression of these genes using RT-qPCR, indicating that the expression levels of Angpt 2 and caspase-3 were significantly reduced $(\mathrm{P}<0.01$ and $\mathrm{P}<0.05$, respectively) in comparison with the $\mathrm{I} / \mathrm{R}+$ Angpt 2 siRNA group (Fig. 6B).

Evaluations of cell viability, cell apoptosis rate and cell migration revealed that FGF21 administration along with Angpt2 knockdown significantly improved cell survival 

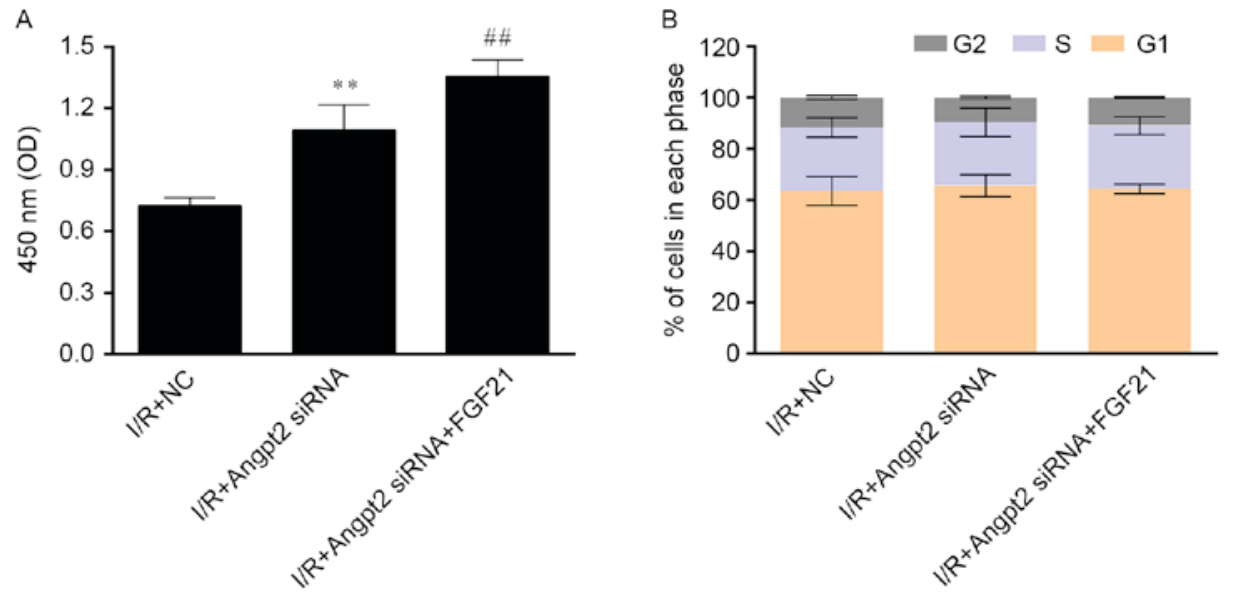

Figure 7. Angpt 2 inhibition promotes the cardioprotective effect of FGF21 by enhancing cell viability. (A) Cell counting kit- 8 assay indicates the cell viability under each experimental condition. The results are representative of the mean of three independent experiments. ${ }^{* *} \mathrm{P}<0.01$ vs. the $\mathrm{I} / \mathrm{R}+\mathrm{NC}$ group; ${ }^{\# \#} \mathrm{P}<0.01$ vs. the I/R+Angpt 2 siRNA group. (B) Cell cycle distributions were measured by flow cytometry, and are presented as the mean of three independent experiments. FGF21, fibroblast growth factor 21; I/R, ischemia/reperfusion; Angpt2, angiopoietin-2; siRNA, small interfering RNA; NC, negative control.

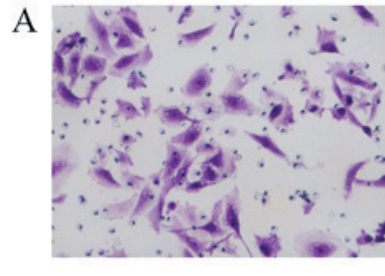

$\mathrm{I} / \mathrm{R}+\mathrm{NC}$

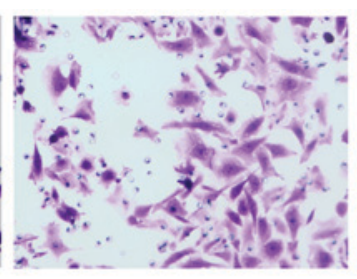

I/R+Angpt2 siRNA

B
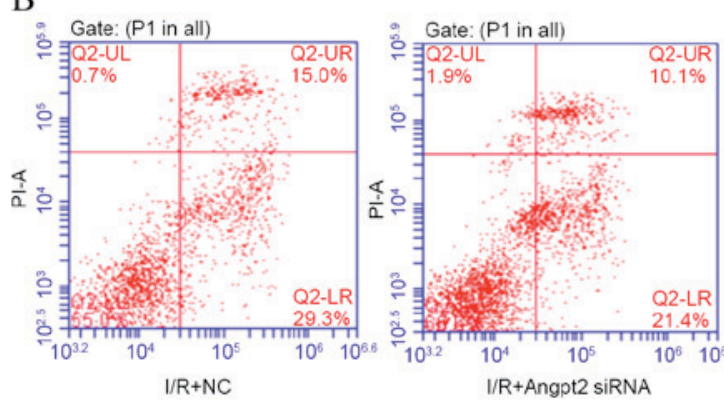

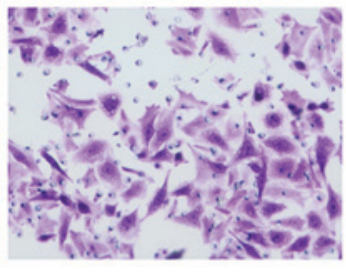

I/R+Angpt2 siRNA+FGF21
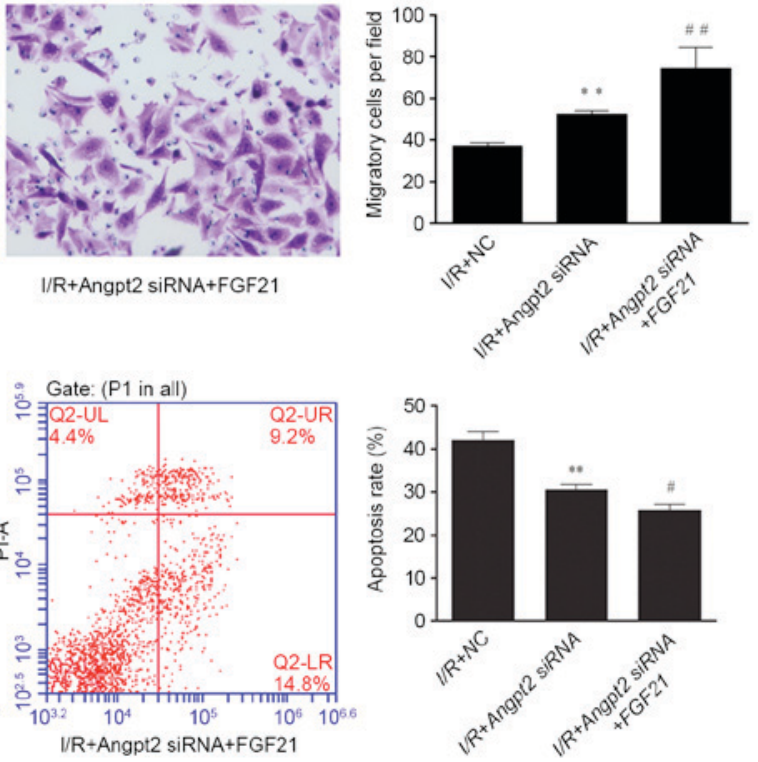

Figure 8. Angpt2 inhibition promotes the cardioprotective effect of FGF21 by reducing apoptosis and increasing cell migration ability. (A) Representative images of five independent experiments of Transwell cell migration assay are shown for each group. The mean of cell migration per field ( $\mathrm{n}=5$ ) is indicated in the bar graph. (B) Mean apoptosis rate was detected by flow cytometry $(\mathrm{n}=3)$. ${ }^{* *} \mathrm{P}<0.01 \mathrm{vs}$. the $\mathrm{I} / \mathrm{R}+\mathrm{NC}$ group; ${ }^{\#} \mathrm{P}<0.05$ and ${ }^{\# \prime} \mathrm{P}<0.01 \mathrm{vs}$. the $\mathrm{I} / \mathrm{R}+\mathrm{Angpt} 2$ siRNA group. FGF21, fibroblast growth factor 21; I/R, ischemia/reperfusion; Angpt2, angiopoietin-2; siRNA, small interfering RNA; NC, negative control.

compared with Angpt2 knockdown alone ( $\mathrm{P}<0.01$; Fig. 7A), whereas transfection and treatment did not markedly affect the cell cycle distribution following I/R (Fig. 7B). FGF21 exposure with Angpt 2 knockdown also significantly improved the migration ability (Fig. 8A) in comparison with Angpt2 knockdown alone $(\mathrm{P}<0.01)$. Furthermore, the siRNA transfection significantly reduced cell apoptosis compared with the control $(\mathrm{P}<0.01)$, and FGF21 treatment inducing significant further reduction compared with the Angpt2 siRNA group ( $\mathrm{P}<0.05$; Fig. 8B).

\section{Discussion}

The development of I/R-induced injury in the heart has been considered as a complicated pathological process, which ranges from the cellular level to the organism level. A large number of regulators and pathways have been reported to be involved in the pathophysiology of I/R-induced injury, and the role of each pathway and the exact mechanisms of I/R-induced injury remain controversial (19).

In general, cardioprotective responses against I/R-induced injury do not only occur in the heart itself, but also systemic responses are observed. Several previous studies have suggested that the liver responds to I/R-induced injury in the heart via upregulation of cardioprotective secretory factors $(20,21)$, including endocrine factor FGF21. Evidence has been provided that FGF21 protects the heart from I/R-induced injury (22). Patel et al reported that cardiomyocytes can also secret FGF21, and autocrine/paracrine FGF21 can stimulate further production and secretion of FGF21 
during I/R-induced injury, thus promoting its cardioprotective effect in the heart (23). A comprehensive proteomic analysis by Cong et al also identified that FGF21 protects against I/R-induced injury in cardiomyocytes through the activation of the Akt-GSK-3 $\beta$-caspase-3 pathway and modulation of the key factors for energy supply (24).

In the present study, treatment with FGF21 markedly increased cell survival by suppression of apoptosis. In addition, the cell migration ability was also improved by FGF21 treatment during simulated I/R. Cell migration contributes to the adaptive response during I/R-induced injury (25), which may induce the regeneration of cardiomyocytes and repair of heart injury (26). According to the data from western blot and qPCR, FGF21 significantly reduced the expression of caspase-3, which suggested the interruption of downstream signaling of apoptosis during I/R-induced injury. This result provided evidence supporting the theory that FGF21 prevents apoptosis during I/R-induced injury via the Akt-GSK-3 $\beta$-caspase-3 signaling pathway, leading to the inhibition of apoptosis (27).

Previous studies have demonstrated that the expression of important regulators of energy metabolism is increased by FGF21, such as the expression of ATP-synthase (28), pyruvate kinase (24) and GLUT1 (29). However, in contrast to those studies, the western blot and qPCR data of the present study detected a decreased level of GLUT1, which may result from the upregulated Angpt 2 expression following simulated I/R. GLUT1 expression can be induced by the FGFR (tyrosine kinase)-ERK1/2-Akt signaling pathway (11), while Angpt2 is an inhibitor of different classes of tyrosine kinase (15). Thus, during simulated I/R injury, increased level of Angpt 2 may inhibit FGFR activation, leading to interruption of GLUT1 expression, which consequently results in a passive influence on the cardioprotective effect of FGF21 treatment. Therefore, the current study sought to inhibit Angpt2 expression by siRNA transfection in order to determine the role of Angpt2 in the cardioprotective effect of FGF21.

Angpt2 suppresses the binding of Angpt1 and TEK tyrosine kinase, inhibiting the process of angiogenesis and leading to tissue damage and injury (30). It has been reported that Angpt2 levels are rapidly raised in injury of the heart (31). A number of clinical studies have also suggested that Angpt2 may be applied as a biomarker or predictor for several types of heart injury, including heart failure (13) and coronary heart disease (32). In the present study, using Angpt2 siRNA along with FGF21 administration, we showed an improved level of cell survival and cell migration ability, which supports the hypothesis that inhibition of Angpt2 promoted the cardioprotective effect of FGF21. Biochemistry analysis indicated that GLUT1 levels were significantly increased following transfection with Angpt2 siRNA. These results provided strong evidence supporting our hypothesis that increased level of GLUT1 caused by Angpt 2 inhibition improves the glucose transportation and energy supply, resulting in a more efficient cardioprotective effect of FGF21 against I/R-induce injury in cardiomyocytes.

To the best of our knowledge, the present study is the first to determine the factor that influences the cardioprotective effect of FGF21. Notably, overexpression of Angpt2 in heart injury attenuated the cardioprotective effect of FGF21 treatment through inhibition of GLUT1 expression induced by the FGFR-ERK1/2-Akt signaling pathway. In addition, selective knockdown of Angpt2 using siRNA markedly improved the cardioprotective efficiency of FGF21 against I/R-induced injury, suggesting a potential combination treatment for I/R-induced injury in the heart. Combined application of pharmacological compounds is a classic and simple form of combination therapy, which targets multiple mechanisms and factors contributing to the pathogenesis of certain diseases (33), such as heart diseases. The protective effects of pharmacological compounds targeting different mechanisms can achieve additional or synergistic protection against the disease (33). A classic example of combination therapy for heart diseases is the therapeutic strategy that includes diuretics, $\beta$-blockers, ACE inhibitor, calcium channel blockers and other agents (34). Recent studies have demonstrated a synergistic protection against I/R-induced injury via several mechanisms contributing the contractile protein degradation (35). In the current study, both Angpt2 siRNA and FGF21 were found to exert a cardioprotective effect, since overexpression of Angpt 2 is harmful to the cardiovascular system and endocrine FGF21 has beneficial effects in heart injury. Combination of Angpt 2 siRNA and FGF21 achieves additional cardioprotection against I/R-induced injury, which results from the targeting of specific mechanisms by the two compounds and the promoting effect of Angpt 2 siRNA in FGF21 administration.

In conclusion, the present study provides evidence supporting that FGF21 treatment protects cardiomyocytes from I/R-induced injury. However, increased level of Angpt2 inhibited GLUT1 expression, which serves a passive role in the cardioprotective effect of FGF21 against I/R-induced injury. Combination therapy of FGF21 and Angpt2 siRNA provided more efficient cardioprotection through Angpt2 inhibition and induced GLUT1 upregulation, resulting in improvement of energy supply, increased cell migration and lower apoptosis rate. These results may suggest a novel therapeutic strategy for $\mathrm{I} / \mathrm{R}$-induced injury in the future.

\section{Acknowledgements}

This study was supported by a grant from the National Natural Science Foundation of China (no. 81070227).

\section{References}

1. Ambrose JA and Singh M: Pathophysiology of coronary artery disease leading to acute coronary syndromes. F1000Prime Rep 7: 08, 2015.

2. Hausenloy DJ and Yellon DM: Myocardial ischemia-reperfusion injury: A neglected therapeutic target. J Clin Invest 123: 92-100, 2013 .

3. de Groot H and Rauen U: Ischemia-reperfusion injury: Processes in pathogenetic networks: A review. Transplant Proc 39: 481-484, 2007.

4. Boag SE, Das R, Shmeleva EV, Bagnall A, Egred M, Howard N, Bennaceur K, Zaman A, Keavney B and Spyridopoulos I: T lymphocytes and fractalkine contribute to myocardial ischemia/reperfusion injury in patients. J Clin Invest 125: 3063-3076, 2015.

5. Zitta K, Meybohm P, Bein B, Gruenewald M, Lauer F, Steinfath M, Cremer J, Zacharowski K and Albrecht M: Activities of cardiac tissue matrix metalloproteinases 2 and 9 are reduced by remote ischemic preconditioning in cardiosurgical patients with cardiopulmonary bypass. J Transl Med 12: 94, 2014. 
6. He K, Yan L, Pan CS, Liu YY, Cui YC, Hu BH, Chang X, Li Q, Sun K, Mao XW, et al: ROCK-dependent ATP5D modulation contributes to the protection of notoginsenoside NR1 against ischemia-reperfusion-induced myocardial injury. Am J Physiol Heart Circ Physiol 307: H1764-H1776, 2014.

7. Sawicki G: Synergistic effect of inhibitors of MMPs and ROS-dependent modifications of contractile proteins on protection hearts subjected to oxidative stress. Curr Pharm Des 20 $1345-1348,2014$

8. Fukumoto S: Actions and mode of actions of FGF19 subfamily members. Endocr J 55: 23-31, 2008

9. Wente W, Efanov AM, Brenner M, Kharitonenkov A, Köster A, Sandusky GE, Sewing S, Treinies I, Zitzer H and Gromada J: Fibroblast growth factor-21 improves pancreatic beta-cell function and survival by activation of extracellular signal-regulated kinase 1/2 and Akt signaling pathways. Diabetes 55: 2470-2478, 2006.

10. Liu SQ, Roberts D, Kharitonenkov A, Zhang B, Hanson SM, Li YC, Zhang LQ and Wu YH: Endocrine protection of ischemic myocardium by FGF21 from the liver and adipose tissue. Sci Rep 3: 2767, 2013

11. Ge X, Chen C, Hui X, Wang Y, Lam KS and Xu A: Fibroblast growth factor 21 induces glucose transporter-1 expression through activation of the serum response factor/Ets-like protein-1 in adipocytes. J Biol Chem 286: 34533-34541, 2011.

12. Syrjälä SO, Tuuminen R, Nykänen AI, Raissadati A, Dashkevich A, Keränen MA, Arnaudova R, Krebs R, Leow CC, Saharinen $\mathrm{P}$, et al: Angiopoietin-2 inhibition prevents transplant ischemia-reperfusion injury and chronic rejection in rat cardiac allografts. Am J Transplant 14: 1096-1108, 2014.

13. Lukasz A, Beutel G, Kümpers P, Denecke A, Westhoff-Bleck M, Schieffer B, Bauersachs J, Kielstein JT and Tutarel O: Angiopoietin-2 in adults with congenital heart disease and heart failure. PLoS One 8: e66861, 2013.

14. Pöss J, Ukena C, Kindermann I, Ehrlich P, Fuernau G, Ewen S, Mahfoud F, Kriechbaum S, Böhm M and Link A: Angiopoietin-2 and outcome in patients with acute decompensated heart failure. Clin Res Cardiol 104: 380-387, 2015.

15. Scholz A, Plate KH and Reiss Y: Angiopoietin-2: A multifaceted cytokine that functions in both angiogenesis and inflammation. Ann NY Acad Sci 1347: 45-51, 2015.

16. Winter SF, Acevedo VD, Gangula RD, Freeman KW, Spencer DM and Greenberg NM: Conditional activation of FGFR1 in the prostate epithelium induces angiogenesis with concomitant differential regulation of Ang-1 and Ang-2. Oncogene 26: 4897-4907, 2007.

17. Lu Z, Chen Y, Li L, Wang G, Xue H and Tang W: Combination therapy of renin-angiotensin system inhibitors plus calcium channel blockers versus other two-drug combinations for hypertension: A systematic review and meta-analysis. J Hum Hypertens 31: 1-13, 2017.

18. Livak KJ and Schmittgen TD: Analysis of relative gene expression data using real-time quantitative PCR and the 2(-Delta Delta C(T)) Method. Methods 25: 402-408, 2001.

19. Yellon DM and Hausenloy DJ: Myocardial reperfusion injury. N Engl J Med 357: 1121-1135, 2007.

20. Liu SQ, Tefft BJ, Roberts DT, Zhang LQ, Ren Y, Li YC, Huang Y, Zhang D, Phillips HR and Wu YH: Cardioprotective proteins upregulated in the liver in response to experimental myocardial ischemia. Am J Physiol Heart Circ Physiol 303: H1446-H1458, 2012 .
21. Liu SQ and Wu YH: Liver cell-mediated alleviation of acute ischemic myocardial injury. Front Biosci (Elite Ed) 2: 711-724, 2010.

22. Planavila A, Redondo-Angulo I and Villarroya F: FGF21 and Cardiac Physiopathology. Front Endocrinol (Lausanne) 6: 133, 2015.

23. Patel V, Adya R, Chen J, Ramanjaneya M, Bari MF, Bhudia SK, Hillhouse EW, Tan BK and Randeva HS: Novel insights into the cardio-protective effects of FGF21 in lean and obese rat hearts. PLoS One 9: e87102, 2014.

24. Cong WT, Ling J, Tian HS, Ling R, Wang Y, Huang BB, Zhao T, Duan YM, Jin LT and Li XK: Proteomic study on the protective mechanism of fibroblast growth factor 21 to ischemia-reperfusion injury. Can J Physiol Pharmacol 91: 973-984, 2013.

25. Zhang Y, Li H, Wei R, Ma J, Zhao Y, Lian Z and Liu Z: Endothelial cells regulate cardiac myocyte reorganisation through $\beta 1$-integrin signalling. Cell Physiol Biochem 35: 1808-1820, 2015.

26. Qian H, Yang Y, Li J, Huang J, Dou K and Yang G: The role of vascular stem cells in atherogenesis and post-angioplasty restenosis. Ageing Res Rev 6: 109-127, 2007.

27. Tanajak P, Chattipakorn SC and Chattipakorn N: Effects of fibroblast growth factor 21 on the heart. J Endocrinol 227: R13-R30, 2015.

28. Ji K, Zheng J, Lv J, Xu J, Ji X, Luo YB, Li W, Zhao Y and Yan C: Skeletal muscle increases FGF21 expression in mitochondrial disorders to compensate for energy metabolic insufficiency by activating the mTOR-YY1-PGC1 $\alpha$ pathway. Free Radic Biol Med 84: 161-170, 2015.

29. Moyers JS, Shiyanova TL, Mehrbod F, Dunbar JD, Noblitt TW, Otto KA, Reifel-Miller A and Kharitonenkov A: Molecular determinants of FGF-21 activity-synergy and cross-talk with PPARgamma signaling. J Cell Physiol 210: 1-6, 2007.

30. Fiedler U, Krissl T, Koidl S, Weiss C, Koblizek T, Deutsch U, Martiny-Baron G, Marmé D and Augustin HG: Angiopoietin-1 and angiopoietin-2 share the same binding domains in the Tie-2 receptor involving the first Ig-like loop and the epidermal growth factor-like repeats. J Biol Chem 278: 1721-1727, 2003.

31. Lorbeer R, Baumeister SE, Dörr M, Nauck M, Grotevendt A, Volzke H, Vasan RS, Wallaschofski H and Lieb W: Circulating angiopoietin-2, its soluble receptor Tie-2, and mortality in the general population. Eur J Heart Fail 15: 1327-1334, 2013.

32. Wang X, Yong H, Mi L, Bai Y, Guo L, Gao W, Cui M and Zhang Y: Changes and significance of serum angiopoietin-2 levels in patients with coronary heart disease. Biomarkers 17: 745-749, 2012.

33. Piccolo MT, Menale C and Crispi S: Combined anticancer therapies: An overview of the latest applications. Anticancer Agents Med Chem 15: 408-422, 2015.

34. Smith R, McCready T and Yusuf S: Combination therapy to prevent cardiovascular disease: Slow progress. JAMA 309 1595-1596, 2013.

35. Cadete VJ,Arcand SA,Lin HB and Sawicki G: Synergistic protection of MLC 1 against cardiac ischemia/reperfusion-induced degradation: A novel therapeutic concept for the future. Future Med Chem 5: 389-398, 2013. 